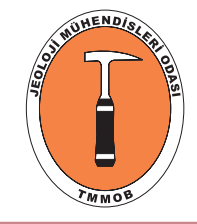

\author{
Türkiye Jeoloji Bülteni \\ Geological Bulletin of Turkey \\ 63 (2020) 225-240 \\ doi: $10.25288 /$ tjb.612106
}

\title{
Susuzdağ ve Tekkedağ (Kapadokya-Türkiye) Çevresindeki Volkanik Kayaçların ASTER Görüntüsü Kullanılarak Haritalanması
}

Mapping of Volcanic Rocks Around Susuzda $\breve{g}$ and

Tekkedağ (Cappadocia-Turkey) Using ASTER image

\section{Aziz Özyavaş $\mathbb{D}$}

\author{
Kocaeli Üniversitesi Mühendislik Fakültesi Jeoloji Mühendisliği Bölümü, 41380, Kocaeli
}

\author{
• Geliş/Received: 27.08.2019 • • Düzeltilmiş Metin Geliş/Revised Manuscript Received: 24.12.2019 • Kabul/Accepted: 10.01 .2020 \\ • Çevrimiçi İlk Yayın/Available online: 01.03.2020 • • Baski/Printed: 01.04.2020 \\ Araştırma Makalesi/Research Article Türkive Jeol. Bül. / Geol. Bull. Turkey
}

Öz: Tuz Gölü ve Ecemiş Fayı arasında ve Kapadokya Volkanik Bölgesinde bulunan inceleme alanı, geç dönem teknonizmasından etkilenmiş ve buna bağlı olarak geç Miyosen'den günümüze kadar gelişen volkanik aktiviteye maruz kalmıştır. Bu çalışmada, Terra uydusu üzerindeki Gelişmiş Uydu Isıl Yayım ve Yansıtım Radyometre (ASTER) algılayıcısı tarafından elde edilmiş multispektral uydu görüntüsü kullanılarak Orta Anadolu'da Susuzdağ (Hamurcu, Kayseri) ve Tekkedağ’ı (Başdere, Nevşehir) içine alan bir bölgede yüzeylenmiş olan volkanik kayaçlar haritalanmıştır. ASTER'in bölgedeki kayaçların karakteristik Fe, Al-OH ve Fe/Mg-OH soğurma bantlarına karşılık gelen bantları dikkate alınarak 9/8, (1+4)/(2+3), 6 ve $(1+4) /(2+3), 8,4 / 6(\mathrm{KYM})$ bant oran görüntüleri oluşturulmuş ve bölgedeki bazalt, bazaltik andezit/andezit, dasit ve piroklastik kayaçların sınırları belirlenmiştir. Özellikle $9 / 8$ bant oranının bazalt ve andezitlerin diğer volkanik kayaçlardan ayrılmasında etkin olduğu görülmüştür. Bununla birlikte $\mathrm{Fe}^{2+}($ ferröz) demir indeksi, $(1+4) /(2+3)$, Hamurcu çevresindeki dasit domlarını belirgin bir şekilde ortaya çıkarmıştır. Bölgede geniş alanları kaplayan İncesu ignimbriti ise ASTER 6.bantına karşılık gelen radyasyonu soğurma özelliğinden dolayı 4/6 bant oranı görüntüsünde çevresindeki kayaçlara göre daha koyu tonlarda görülmüştür. $\mathrm{Bu}$ çalışmada ilk kez kullanılan bant oran görüntüleri sonucu oluşturulan litoloji haritalarının doğruluğu, arazi gözlemleri ve MTA jeoloji haritası ile tasdik edilmiştir. Bazalt ve andezitin birbirinden ayırımı nispeten belirsizlik içermesine rağmen, ASTER'in işlenmiş görüntüleri volkanik kayaçların düşük bir maliyetle, güvenilir ve hızlı bir şekilde haritalanmasına olanak sağlamıştır. Ayrıca bu çalışmada kullanılan metodoloji ülkemizin ve dünyanın benzer coğrafik bölgelerinde magmatik kayaçların haritalanmasında uygulanabilir.

Anahtar Kelimeler: ASTER, Bant oran, Volkanik kayaçlar, Orta Anadolu, Kapadokya, Uzaktan algılama

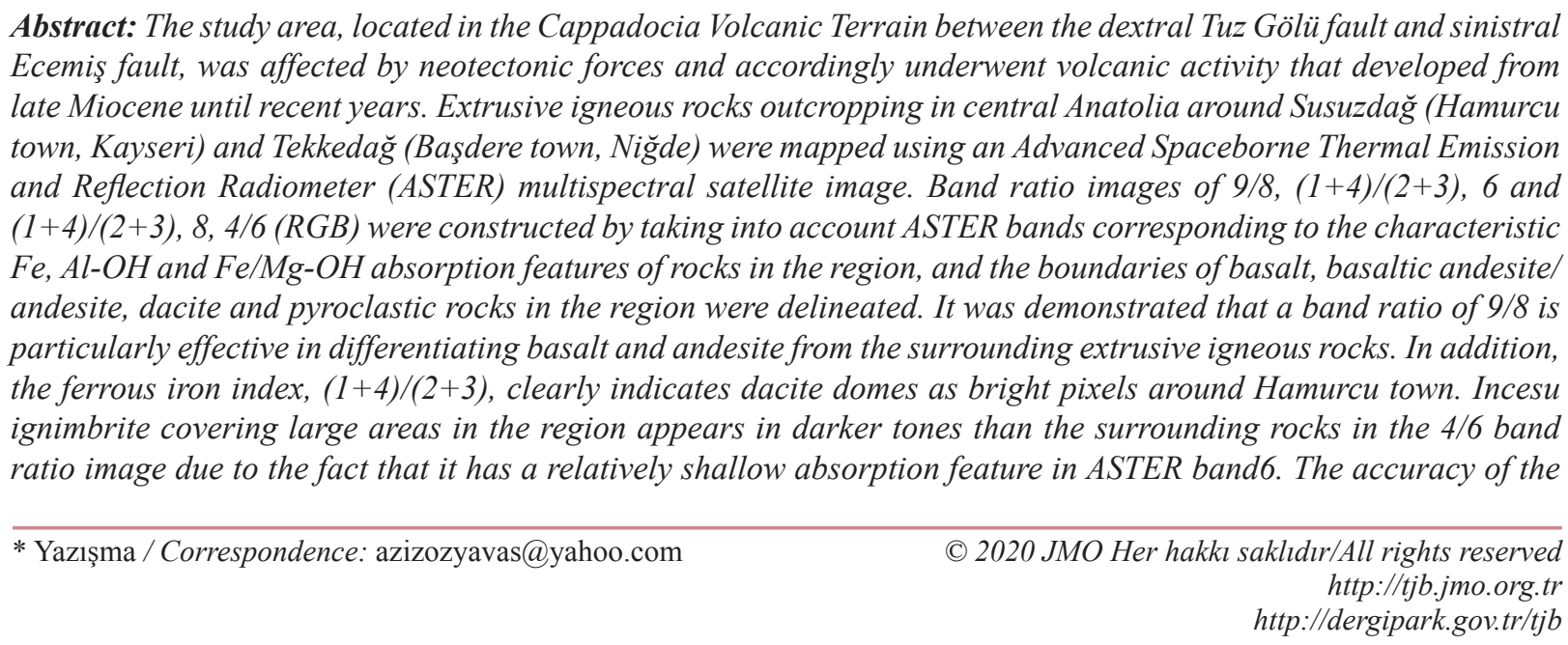


resultant lithological maps generated from the first-time used band ratio images was verified by comparing the field survey and geological maps. Although there is some uncertainty in discriminating between basalt and andesite, the resultant ASTER images enable us to map extrusive igneous rocks in a cost-effective, reliable and fast manner. The methodology used in this study can be applied for mapping igneous rocks in similar geographic locations in Turkey and around the world.

Keywords: ASTER, Band ratio, Extrusive igneous rocks, Central Anatolia, Cappadocia, Remote sensing

\section{GíRiș}

Susuzdağ (Hamurcu beldesi, Kayseri) ve Tekkedağ'1 (Başdere beldesi, Nevşehir) çevreleyen çalışma sahası, Kayseri ilinin B-GB'sında yer almaktadır. Çalışma sahasında Erciyes volkanizmasına ait yaygin olarak bazalt, bazaltik andezit/andezit, dasit ve piroklastik

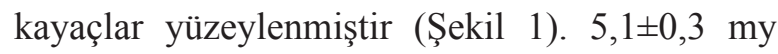
yaşl1 Kızılkaya ignimbriti (Schumacher vd., 1990) Başdere bölgesini içine alan Tekkedağ volkanitinin

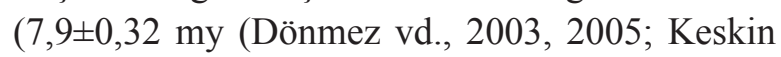
vd., 2010)) güney eteklerine sıvanmış olup, daha önceki volkanitlerin üzerine yerleşmiştir (Akçay

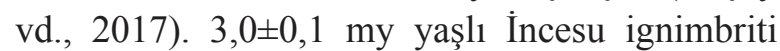
(Innocenti vd., 1975) ise bölgede Sultansazlığ1 Havzasının KB'sındaki Himmetdede ilçesinden (Kayseri) güneydoğuda Toroslara kadar çok geniş bir alana yayılmıştır. Çıkış merkezi Kayseri ilinin güneyinde bulunan Koçdağ olan İncesu ignimbritinin akış yönü $\mathrm{K}, \mathrm{KB}, \mathrm{KD}$, D ve GD yönünde olduğundan Tekkedağ volkanının kuzey yamacına sıvanmış ve G, GB yönünde akamamıştır (Akçay vd., 2017). Susuzdağ çevresindeki volkanik kayaçlarda gerçekleştirilen radyometrik

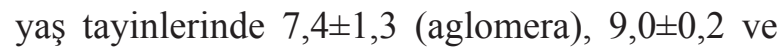
$13,3 \pm 0,3$ my yaşları elde edilmiştir (Dönmez vd., 2003).

Gelişmiş Uydu-bazlı Isıl Yayım ve Yansıtım Radyometre (ASTER) multispektral sensörü Yer Gözlem Sistemi (EOS) Terra platformunda taşınmakta olup Aralık 1999 yılında firlatılmıştır (Yamaguchi ve Naito, 2003). ASTER 0,52 $\mu \mathrm{m}$ ve $0,86 \mu \mathrm{m}$ aralığında görünür-yakın kızılötesi (VNIR), 1,6 $\mu \mathrm{m}$ ve 2,43 $\mu \mathrm{m}$ aralığında kısa dalga kızılötesi (SWIR) ve termal kızılötesi (TIR) $(8,125$ $\mu \mathrm{m}$ 'den 11,65 $\mu$ m'ye kadar) bölgelerinde sirasiyla 15 m, 30 m ve 90 m uzaysal çözünürlüğe sahiptir. ASTER 60 km şerit genişliğinde görüntü elde eder (Fujisada, 1995). MultispektralASTER görüntüleri uzun zamandır farklı coğrafik bölgelerinde bir çok araştırmacı tarafından litoloji ve mineral haritalamada başarılı bir şekilde kullanılmaktadır (Rowan ve Mars, 2003; Yamaguchi ve Naito, 2003; Mars ve Rowan, 2010; Amer vd., 2010; Pour ve Hashim, 2012; Rajendran ve Nasir, 2017).

Benzer bileşime sahip ve alterasyona uğramış magmatik kayaçların uydu görüntüleri kullanılarak haritalanması birtakım zorluklar içermektedir. $\mathrm{Bu}$ çalışmada ASTER'in VNIR ve SWIR bantlarından türetilen ve daha önce literatürde kullanılmamış $9 / 8,(1+4) /(2+3), 6$ ve $(1+4) /(2+3), 8,4 / 6(\mathrm{KYM})$ bant oran görüntüleri oluşturulmuş ve Susuzdağ (Hamurcu beldesi) ve Tekkedağ (Başdere beldesi) çevresindeki volkanik kayaçlar haritalanmıştır. Hamurcu ve Başdere çevresinin seçilmesinin nedeni; (1) daha önce bu bölgede uydu görüntüleri kullanılarak litolojik haritalama yapılmaması ve (2) uzaktan algılama açısından elverişli olmasıdır (arazinin nispeten az bitki örtüsü içermesi ve kayaçların mostra vermesidir). ASTER görüntüsünden oluşturulan litoloji haritalarının doğruluğu hem arazi gözlemlerine ve hem de MTA jeoloji haritası değerlendirilerek tasdik edilmiştir. 


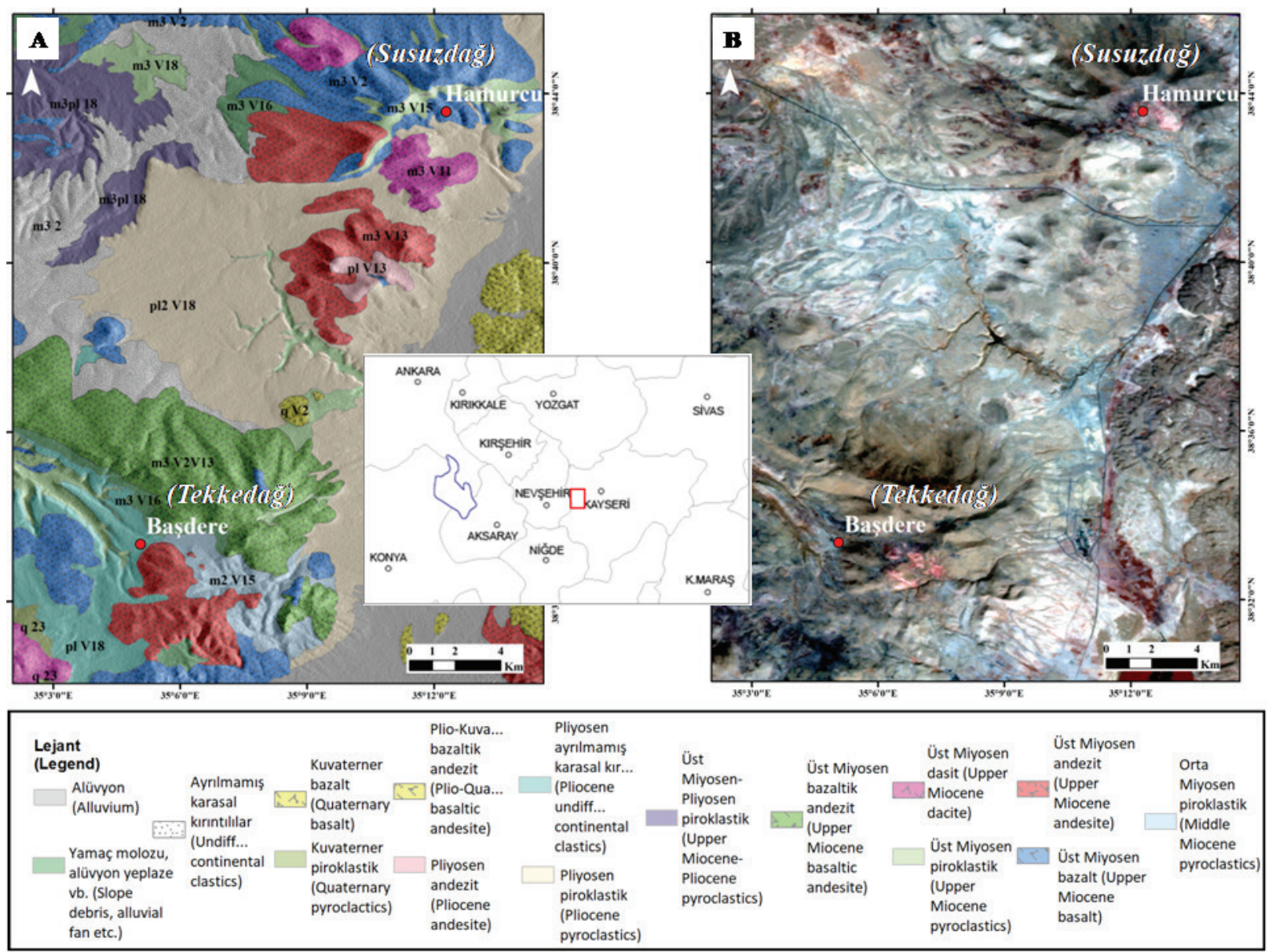

Şekil 1. (A) Hamurcu (Susuzdağ) ve Başdere beldelerini (Tekkedağ'ı) içine alan alan bölgenin jeoloji haritası. (B) ASTER görüntüsünün bir kısmının bölgeyi içine alan 468 (KYM) yanlış renk bileşik görüntüsü ve çalışma sahasının lokasyonunu gösteren harita (kırmızı dikdörtgen).

Figure 1. (A) Geological map of area covering Hamurcu (Susuzdağ) and Başdere towns (Tekkedağ). (B) Subset of a 468 (RGB) false color composite ASTER image of the region and map showing location of study area (red rectangle).

\section{BÖLGENIN JEOLOJISİ}

Çalışma sahasını da içine alan bölge, Anatolid tektonik birlikleri üzerinde yer almaktadır. Anatolidler içerisinde yer alan Orta Anadolu Kristalen Karmaşı ğı (OAKK), metamorfik çekirdek ve bunun zarfi ile bu birimleri kesen farklı kökenlere sahip Üst Kretase yaşlı (110-65 my arası) granitoidlerden oluşmuştur (Delibaş ve Genç, 2012). Bölgenin stratigrafisini bu birimleri farklı lokasyonlarda üzerleyen Üst Kretase sonrası oluşmuş çeşitli havza çökelleri ve ofiyolitik birimler tamamlar (Idleman vd., 2014). İzmirAnkara Okyanusunun Kretase boyunca kapanmas1 sırasında pasif kita kenarı pozisyonunda olan OAKK birimlerinin üzerine itilen ofiyolit birimleri ve okyanusal yay ile çarpışması nedeniyle kabuk kalınlaşması ve yüksek sıcaklık metamorfizmasına uğramış olduğu düşünülür (Göncüoğlu, 2010). Geç Kretase'ye kadar bölgede gelişen sıkışmalı tektonizma, kıta kabuğunda kısalmaya ve plüton yerleşimine sebep olurken (Genç ve Yürür, 2010), geç Kretase sonrası ekstansiyonal teknonizma 
kabuğu gerip inceltmiş ve OAKK'nın metamorfik temelinin yükselmesine yol açmıştır (Seyitoğlu ve Scott, 1996).

Türkiye'de gelişen volkanizma Neotetis'in dalma-batması ve kapanmasiyla yakından ilişkilidir. Batıdan doğuya doğru ilerleyen volkanik aktivite, Neojen ve Kuvaterner'de Bat1 Anadolu, Galatya, Kapadokya (orta Anadolu), doğu Anadolu volkanik bölgelerinin gelişmesine neden olmuştur (Pasquare vd., 1988; Toprak vd., 1994). Kapadokya Volkanik Bölgesi (KVB), Avrasya ile Afro-Arab levhalarının geniş bir bölgede orta-geç Miyosen ve Kuvaterner süresince yakınlaşıp çarpışması sonucu oluşmuş kıtasal yay arkası havzasıdır (Innocenti vd., 1975; Rotstein ve Kafka, 1982). KVB, kalınlığ1 2 km'yi bulan başlıca volkanik kül ve iri kaya blokları içeren piroklastik akıntılar, flüvyal ve göl çökelleri, andezitik-riyolitik-bazaltik lavlar ve lav domlarından oluşmuştur. Bölge yaşları orta Miyosen'den tarih öncesi çağlara uzanan $(13,7$ my $-15.500 \pm 2.500$ yıl $)$ çok sayıda sinder konileri, monojenetik volkanlar, endojenik/ ekzojenik domlar ve Hasandağ, Melendiz ve Erciyes gibi birçok kompozit volkanlar tarafindan şekillendirilmişitr (Innocenti vd., 1975; Pasquare, 1968; Batum, 1978; Ercan, 1986; Pasquare vd., 1988). Bir dizi KB-gidişli sağ-yönlü doğrultu atımlı fay KVB'yi kesip birçok bloğa ayırmıştır. Bununla birlikte, KVB'yi iki bloğa ayıran en genç fay sistemi kıtaiçi Orta Anadolu Fay zonudur. Bu fay zonunun içinde yaklaşık olarak K-G yönünde uzanan Erciyes çek-ayır havzası yer almaktadır (Koçyiğit ve Erol, 2001). Kayseri çek-ayır havzasının kuzey kısmında bulunan ve morfolojik görünümüyle kalderayı andıran Hamurcu ve Başdere çevresini kapsayan çalışma alanı KDGB yönünde yaklaşık $300 \mathrm{~km}$ uzanan KVB içinde yer alır. (Ak vd., 2015). KVB'nin K-G, KB-GD ve KD-GB yönelimli faylardan oluşmuş olan Tuz Gölü ve Ecemiş Fay sistemlerinin etkisi altında kaldığı düşünülmektedir (Toprak, 1998; Dhont vd., 1998). Pasquare vd. (1988)
KVB'nin jeolojik evriminde üç ana dönem önermiştir. İlk dönem çoğunlukla andezitik bileşimli efüzif ve endojen domların oluştuğu 13,5 ile 8,5 my arasındaki priyodu kapsamaktadır. İkinci periyot (8,5-9 ile 2,7 my) KeçiboyduranMelendiz volkanik kompleksinin oluşumunu ve ignimbirit birimlerinin Ürgüp Havzası/Nevşehir Platosu'nda geniş alanlara yerleştiği dönemdir. $\mathrm{Bu}$ ignimbirit birimleri karasal çökellerle (gölsel ve akarsu) $400 \mathrm{~m}$ kalınlığa ulaşan ara katmanlı çökelleri oluşturmuştur. Üçüncü dönem ise büyük volkan konilerinin oluşumu (Erciyes ve Hasan dağ kompozit volkanları) ile birlikte çok sayıda monojenetik volkan merkezleri ile karakterize edilmiştir.

\section{BÖLGEDEKİ KAYAÇLARIN ÖZELLIKKLERİ}

KVB'de bulunan volkanik kayaçlar genellikle kalk-alkalen bileşime sahiptir (Toprak vd., 1994). Skorya konileri, lav akıntıları, maar, silisik domlar, strato-volkanlar (Erciyes, Hasandağ ve Melendiz) ve geniş alanları kaplayan ignimbiritler KVB'de oldukça yagındır (Le Pennec vd., 1994; 2005). Farklı derecelerde kaynaşmış, üç farklı seviyeden oluşan ve KVB içinde en geniş yayılm gösteren piroklastik kayaç İncesu ignimbiritidir (Schumacher vd., 2004; Koralay ve Kadıoğlu 2003). Riyolit/riyodasit-dasit bileşimli ve ortayüksek potasyum içerikli gri-pembemsi İncesu ignimbiriti kalk-alkalen karaktere sahiptir (Koralay, 2006). İncesu ignimbiriti çok iyi kaynaşmış orta seviyesinin altında vitrofirik olup, üst kısmında düzleşmiş pamis ve altere olmuş ksenolitlerden meydana gelmiştir (Toprak vd., 1994). Ayrica, İncesu ignimbiritinde volkan cam ve litik bilelşenler görülmekte olup, tüm seviyerinde plajioklas, piroksen, opak minerallerine ilave olarak daha az oranda da olsa kuvars, biyotit ve amfibol mineralleri bulunmaktdır (Koralay, 2006). Tekkedağ volkanik kompleksi Erciyes volkanik kompleksinin batısında 9-10 km çapında dairesel bir yapıdır. Tekkedağ volkanik kompleksi 
genç ignimbirit ve bazalt lavları ile kaplıdır. Kompleksin ana kütlesini andezitik lav akıntıları ve piroklastik kayaçlar oluşturmaktadır. Hamurcu volkanik kompleksi (Susuzdağ), Tekkedağ volkanik kompleksine benzer șekilde, andezitik bileşime sahip 8-10 km çapında dairesel formdadır (Toprak vd., 1994). Susuzdağ ve çevresinde üst Miyosen yaşlı altera olmuş andezit-dasitler ile aglomera-breşler yüzeylenirken, bazalt-bazaltik andezitler, üst Miyosen yaşlı dasidik domlar ve Pliyosen yaşlı İncesu tüf-ignimbiritleri Tekkedağ volkanitleri olarak adlandırılan birimleri meydana getirmektedir (Türkecan vd., 2003; Ak vd., 2015). Tekkedağ volkanitlerinin bir kısmını oluşturan siyah-kahverengi bazaltlar opak minerallerce zengin bir hamurdan ve plajioklas, klinopiroksen, olivin ve ortopiroksen fenokristallerden oluşmuştur. Tekkedağ volkanitleri kuzeyde incesu ignimbiriti ile Kızılkaya ignimbiritini ayırır. Tekkedağ volkanik kayaçlarından olan altere olmamış koyu gri-siyah renkli bazaltik andezitler, plajioklas, piroksen ve olivin fenokristallerinden oluşan porfirik bir doku gösterir (Türkecan vd., 2003). Diğer yandan, bölgedeki andezitler beyaz, açık gri ve sarı renkli olup petrograifk analizlerde porfirik dokuya sahip olduğu belirtilmiştir.
Plajioklas, andezitlerin gerek matriks kısmında gerekse fenokristal olarak en yaygın mineraldir. Bunun yanında, daha az oranda amfibol ve biyotit fenokristalleri de görülmüştür. Hidrotermal alterasyona uğramış andezitlerin dokusu bozulmuş ve killeşme ile birlikte alunit ve demir oksitler gelişmiştir (Ak vd., 2015). Susuzdağ genellikle bazaltik andezit karakterli zirveleri oluşturan lavlardan ve piroklastiklerden (aglomera) oluşmuştur (Türkecan vd., 2003). Lavlar gri-siyah renkli, ince veya belirgin feldispat içermektedir (Ak vd., 2015). Bölgedeki açık gri, pembe renkli ince taneli lavlar, önceki araştırmacılar tarafindan andezit olarak belirtilmesine rağmen, $\mathrm{SiO}_{2}$ oranının yüksek olması nedeniyle dasitik domlar olarak tanımlanmıştır. Viskozitesi düşük ve çıktığ 1 yerde biriken dasit domları, belirgin kuvars mineralleri ve porfirik dokusu ile öne çıkmatadır. Çok miktarda Plajioklas ile birlikte daha az oranda piroksen, amfibol ve biyotit fenokristallerinin bol miktarda plajioklas mikrolitleri, amfibol ve piroksen içeren matriksin içinde bulunduğu belirlenmiştir (Türkecan vd., 2003). Bölgedeki volkanik kayaçların petrografik ve arazi gözlemlerine dayanan özellikleri Tablo 1 'de gösterilmiştir.

Tablo 1. Hamurcu ve Başdere çalışma shaları ve çevresinde bulunan volkanik kayaçların petrografik analiz ve arazi gözlem sonuçları

Table 1. Results of petrographic analysis and field observations of extrusive igneous rocks in and around Hamurcu and Başdere study areas.

\begin{tabular}{|c|c|c|}
\hline Kayaç & Petrografik Analiz & Arazi gözlemleri \\
\hline Bazalt & $\begin{array}{l}\text { Opak minerallerce zengin matriks ve plajioklas, } \\
\text { klinopirosen, olivin ve ortopiroksen fenokristaller }\end{array}$ & Siyah-kahverenkli porfirik dokulu \\
\hline $\begin{array}{l}\text { Bazaltik } \\
\text { andezit }\end{array}$ & Porfirik dokulu, plajioklas, piroksen ve olivin fenokristalleri & Koyu gri-siyah renkli porfirik dokulu \\
\hline Andezit & $\begin{array}{l}\text { Porfirik dokulu, plajioklasca zengin matriks ve plajioklas, } \\
\text { bol miktarda plajioklas ile birlikte daha az oranda amfibol } \\
\text { ve biotit fenokristaller }\end{array}$ & $\begin{array}{l}\text { Beyaz, sarı ve gri renkli altere olmuş, yer yer } \\
\text { sağlam kısımlar gözlenmektedir }\end{array}$ \\
\hline Dasit & $\begin{array}{l}\text { Belirgin kuvars mineralleri ve porfirik dokusu. Matriks } \\
\text { bol miktarda plajioklas mikrolitleri ile amfibol ve piroksen } \\
\text { içerir. Fenokristaller çok miktarda plajioklas yanında daha } \\
\text { az miktarda piroksen, amfibol ve biotitden oluşmuştur }\end{array}$ & Açık gri-pembe renkli porfirik doku \\
\hline İgnimbirit & Plajioklas, piroksen, kuvars, biotit ve amfibol & $\begin{array}{l}\text { Gri-pembemsi renkli volkan camı, pomza, } \\
\text { kristal parçaları ve litik bileşenler }\end{array}$ \\
\hline
\end{tabular}




\section{KAYAÇ VE MINERALLERIN SPEKTRAL ÖZELLIKKLERİ}

Kayaçlar, mineral bileşimi, tane boyu ve yüzeylerindeki ayrışmaya bağlı olarak farklı spektral yansıma ve emisyon özellikleri gösterirler. Volkanik kayaçlarda görülen karakteristik soğurma bantları, kayaçların birincil mineral bileşimi (kuvars, feldspat, amfibol, biotit, piroksen vb.) ve daha sonra gelişen ayrışma ve/ veya alterasyon sonucu gelişmiş olan kaolin, alunit, smektit ve muskovit (serisit) gibi mineral birlikteliklerine atfedilir (Drury, 2001). Magmatik kayaçların spektral yansımaları artan $\mathrm{SiO}_{2}$ içeriği ve/veya azalan mafik minerallerin varlıği ile artar (Hunt vd., 1974). Al-OH ile ilişkilendirilen 2,20 $\mu$ m'deki karakteristik soğurma bandı (ASTER bant6) genellikle kil mineralleri (kaolinit, smektit ve illit) ile muskovitin (serisit) varlığını yansıtır (Chabrillat vd., 2002) (Şekil 2). Mg açısından zengin volkanik kayaçlar (bazalt ve andezit) ise ASTER'in bant8'e karş111k gelen 2,30-2,35 $\mu$ m'de karakteristik ve derin $\mathrm{Mg}-\mathrm{OH}$ soğurma band1 oluştururken (Şekil 2), Mg'ca fakir magmatik kayaçlar (Felsik volkanik tüf, riyolit ve dasit) 2,30-2,35 $\mu \mathrm{m}$ 'de nispeten zayıf veya belirgin bir soğurma bandından yoksundur (Haselwimmer vd., 2010) (Şekil 2). Kayaçların dış yüzeylerinden elde edilen spektralardaki $\mathrm{Al}-\mathrm{OH}$ ve $\mathrm{Fe} / \mathrm{Mg}-\mathrm{OH}$ soğurma bantları, aynı zamanda ayrışma yüzeyinin altındaki taze kayaçtaki önemli miktardaki birincil Al ve Fe/Mg varlığı ile de ilişkilendirilebilir (Zhou ve Wang, 2017). Dolayısıyla, kayacın yüzeyinde ayrışma sonucu oluşan mineraller de litolojilerin belirlenmesinde kullanılabilir (Drury, 2001). Ferrik demir mineralleri morötesi spektrumda $(<0,4 \mu \mathrm{m})$ karakteristik ve derin bir soğurma bandı oluşturur. $\mathrm{Bu}$ soğurma bandının uzun dalga boyu kısmı görünür 1şık spektrumuna uzanır ve özellikle mavi ve yeşil renge karşılık gelen radyasyonu emerek, demir oksit minerallerinin kırmız1, turuncu ve sarı renklere sahip olmasina neden olur (Clark, 1999). Buna karşın, ferröz demir içeren kayaçlar kırmızı ve yakın kızılötesinde geniş bir soğurma bandı oluşturur (Şekil 2) (Rockwell, 2012).

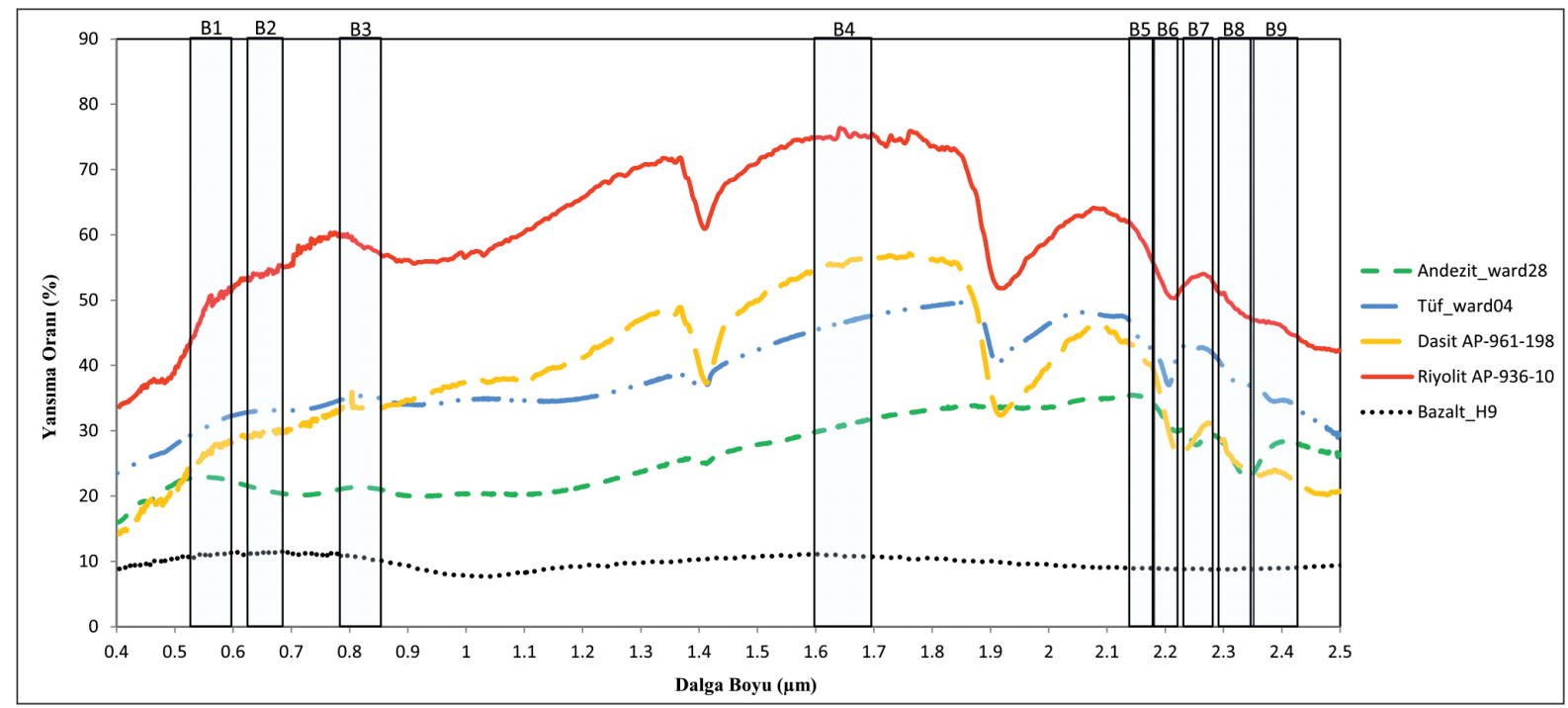

Şekil 2. Çalışma sahasında haritalanmış olan volkanik kayaçların ASTER spektral kütüphanesinden elde edilmiş laboratuar spektral eğrileri (Andezit örneği ward28, tüf örneği ward04, dasit örneği AP-961-198, riyolit örneği AP936-10 ve bazalt örneği H9). Üst kısımdaki numaralar ve barlar ASTER'ın VNIR ve SWIR bantlarının bulunduğu dalga boylarını göstermektedir.

Figure 2. Laboratory spectral curves of the extrusive igneous rocks mapped in the study area obtained from ASTER spectral library (the andezite sample is ward's 28, tuff sample ward's 04, dacite sample AP-961-198, rhyolite sample AP-936-10 and basalt sample H9). The numbers and the corresponding bars above the graph indicate the wavelength locations of ASTER VNIR and SWIR bands. 


\section{VERİ VE YÖNTEM}

$\mathrm{Bu}$ çalışmada kullanılan ASTER L1T verisi 20 Mart 2004 tarihinde elde edilmiş olup minimum bitki, bulut ve kar örtüsüne sahiptir. $\mathrm{Bu}$ verinin seçilme nedeni, ASTER'in VNIR ve SWIR bantlarının kayaçları meydana getiren minerallerin soğurma bantlarına karşılık gelmesidir. Environment for Visualizing Images (ENVI) 5.3 ve Arc geographic information system (GIS) 10.1 yazılımları görüntü işleme ve analizlerinde kullanılmıştır. Bölgenin jeoloji haritası (Şekil 1A) Maden Tetkik ve Arama Genel Müdürlügü'nden, volkanik kayaçların spektraları (Şekil 2) ASTER spektral kütüphanesinden elde edilmiştir. Haziran 2017 tarihinde Hamurcu ve Başdere bölgelerini içine alan bir arazi çalışması yapılmıştır.

ASTER L1T verisi halihazırda ortorektifiye edilmiş ve crosstalk düzeltmesi yapılmıştır. İlk ön işlemolarak, sensörkalibrasyonu dijitalnumaraların radyansa dönüştürülmesiyle gerçekleştirilmiştir. Daha sonra ASTER VNIR bantları $30 \mathrm{~m}$ uzaysal çözünürlüğe tekrar örneklenip, ASTER SWIR bantları ile birleştirilerek toplamda eşit çözünürlüğe sahip VNIR-SWIR aralığında 9 bant elde edilmiştir. ASTER L1T verisine, çok yaygın olarak kullanılan atmosferik düzeltme algoritması olan Fast Line-of-sight Atmospheric Analysis of Hypercubes (FLAASH) uygulanmıştır. Böylece, veri hem aerosol ve su buharinın spektral etkisinden kurtarılmış hem de radyans değerleri yansıma oranına kalibre edilmiştir. Ön işlemler uygulandıktan sonra, ASTER verisinden yanlış renk bileşik görüntüsü ile birlikte (Şekil 1B) bant oranlama tekniği kullanarak iki farklı bant oran görüntüsü elde edilmiştir (Şekil 3 ve 4). Bant oranlama metodu basit ve aynı zamanda tutarlı bir teknikdir (bir banttaki her bir piksel değeri diğer bir bantın aynı pikselinin değerine bölünür). $\mathrm{Bu}$ yöntemle topografik, tane boyu ve güneşin aydınlatma koşullarındaki değişiminin etkisi azaltılarak farklı kayaçların spektral kontrastı artır1lır (Rowan ve Mars, 2003).

\section{TARTIŞMA VE SONUÇLAR}

\section{Yanlış Renk Bileşik Görüntü Analizi}

ASTER 468 (KYM) yanlış renk bileşik görüntüsü arjilik, fillik ve propilitik alterasyonların haritalanmasında kullanılmıştır (Tommaso ve Rubinstein, 2007; Mars, 2010). Bu çalışmada ASTER'ın 468 (KYM) yanlış renk bileşik görüntüsünün alterasyonlar ile birlikte bölgedeki kayaçların ayırt edilmesinde de etkin olduğu görülmüştür (Şekil 1B). ASTER bant6 seçimi Al$\mathrm{OH}$ soğurma bantı gösteren filloslikat mineralleri (kil mineralleri ve muskovit) ile ilişkili iken, bant8 ferromagnezyen minerallerin (piroksen, amfibol, biyotit ve epidot) karakteristik soğurma bantına karșılık gelmektedir (Șekil 2). ASTER 468 (KYM) yanlış renk bileşik görüntüsünde bölgedeki bazalt ve andezit gibi mafik ve ortaç volkanik kayaçların çok önemli bir kısmının kahverengi ile temsil edildiği görülmektedir (örnegin, Hamurcu çevresindeki kaldera) (Şekil 1B). Bunun nedeni, bazalt ve andezit gibi mafik ve ortaç volkanik kayaçların ASTER bant4'de bant6 ve bant8'e göre daha yüksek yansimas1 değerine sahip olmasıdır (bant6'ya karşılık gelen zayıf Al-OH soğurma bantı ve mafik minerallerin ASTER bant8'de sahip olduğu Fe/Mg-OH ile ilişkili derin soğurma bantı) (Şekil 2). Ayrıca, haritalanan sahadaki andezit ve bazaltlarda yer yer çok koyu yeşi1/lacivert tonlar görülmektedir. $\mathrm{Bu}$ alanlar özellikle bant4 ile birlikte genel olarak VNIR-SWIR aralığında yansıma oranında azalma ile ilgilidir ve muhtemelen volkanik kayacin silis $\left(\mathrm{SiO}_{2}\right)$ içeriğinin azalması (daha mafik bileşime sahip olması) ile açıklanabilir (Şekil 1B). Haritalanan bölgede geniş alanları kaplayan İncesu ignimbriti özellikle ASTER bant8'deki göreceli olarak yüksek yansıma değeri nedeniyle (başka bir ifadeyle ASTER bant8'deki zayıf/sı̆g Fe/Mg$\mathrm{OH}$ soğurma bantına sahip olmasi) mavi tonlarda görülmektedir ki bu alanlar çoğunlukla ekili olmayan alanlara karşıl1k gelmektedir (Şekil 1B). Hamurcu ve çevresinde bulunan dasit domları ise, ASTER'ın 6 ve 8. bantlarındaki nispeten yüksek 

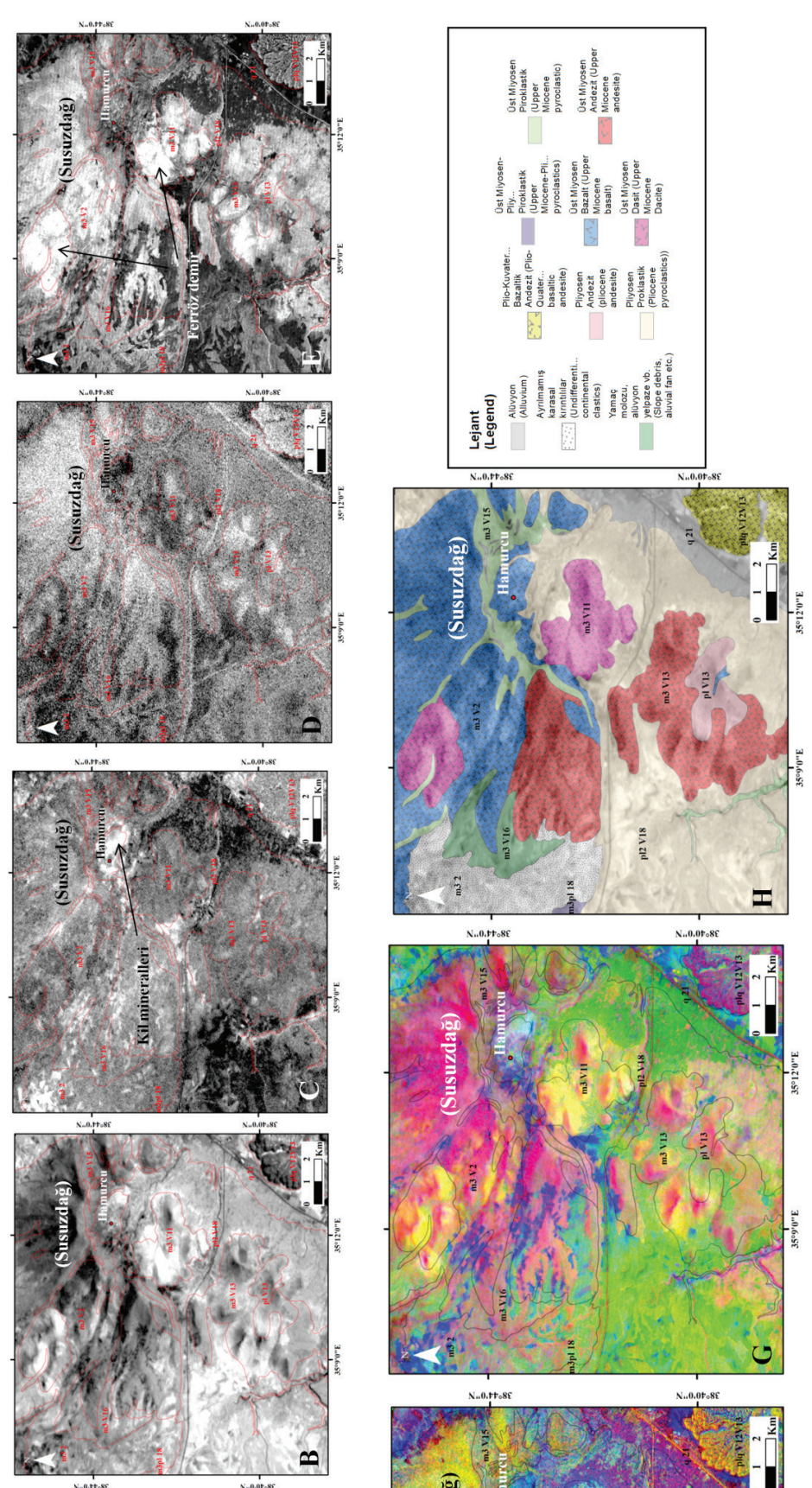

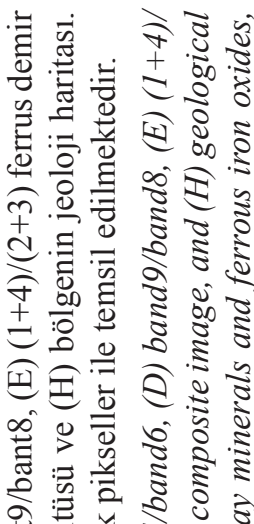

री

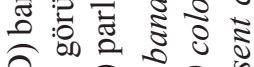

อิ

䒕:

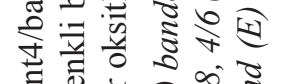

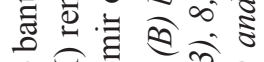

(2)

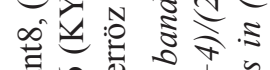

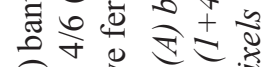

की $\infty$ के

की

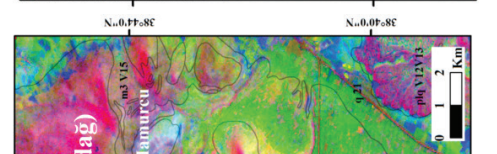

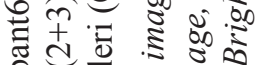

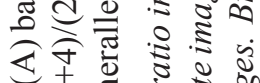

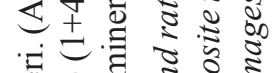

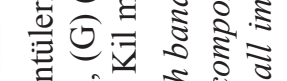
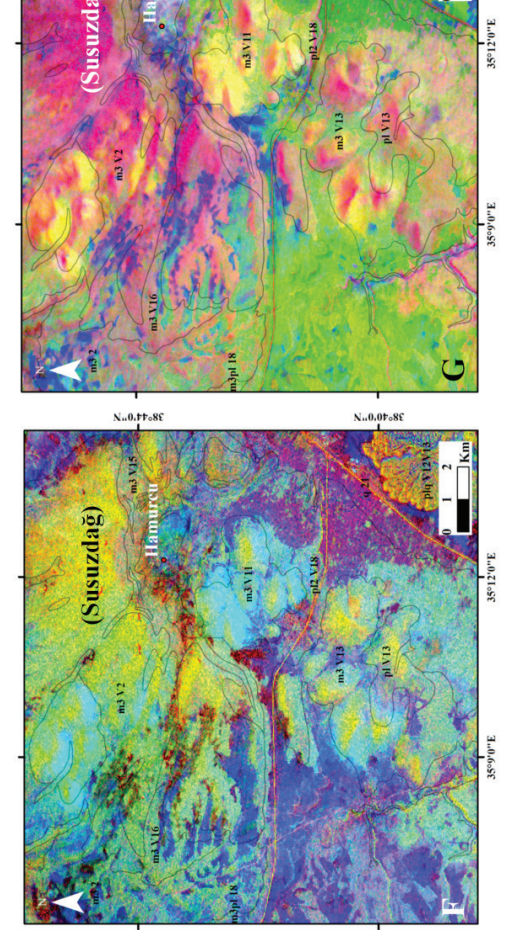

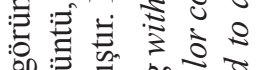

ป :

땋

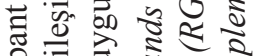

0050 .

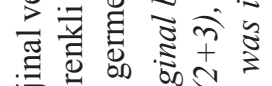

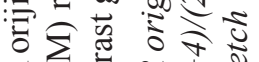

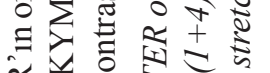

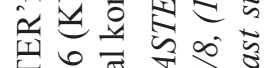

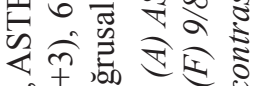

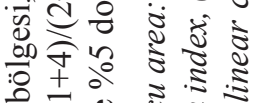

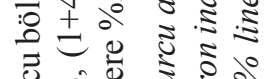

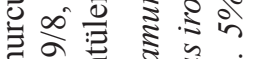

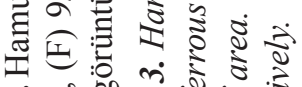

m.

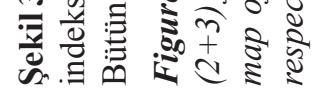



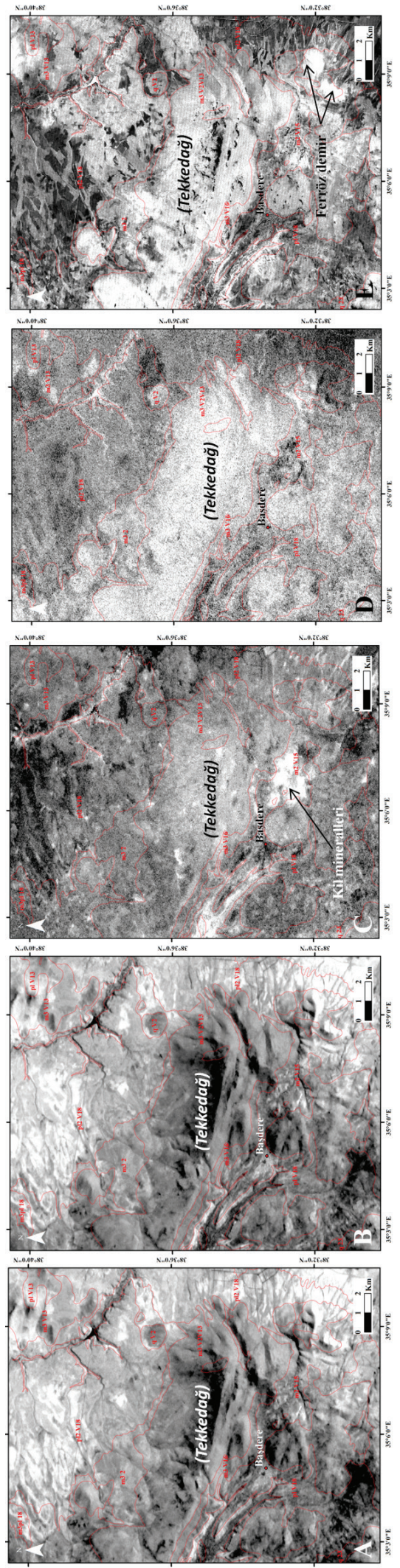
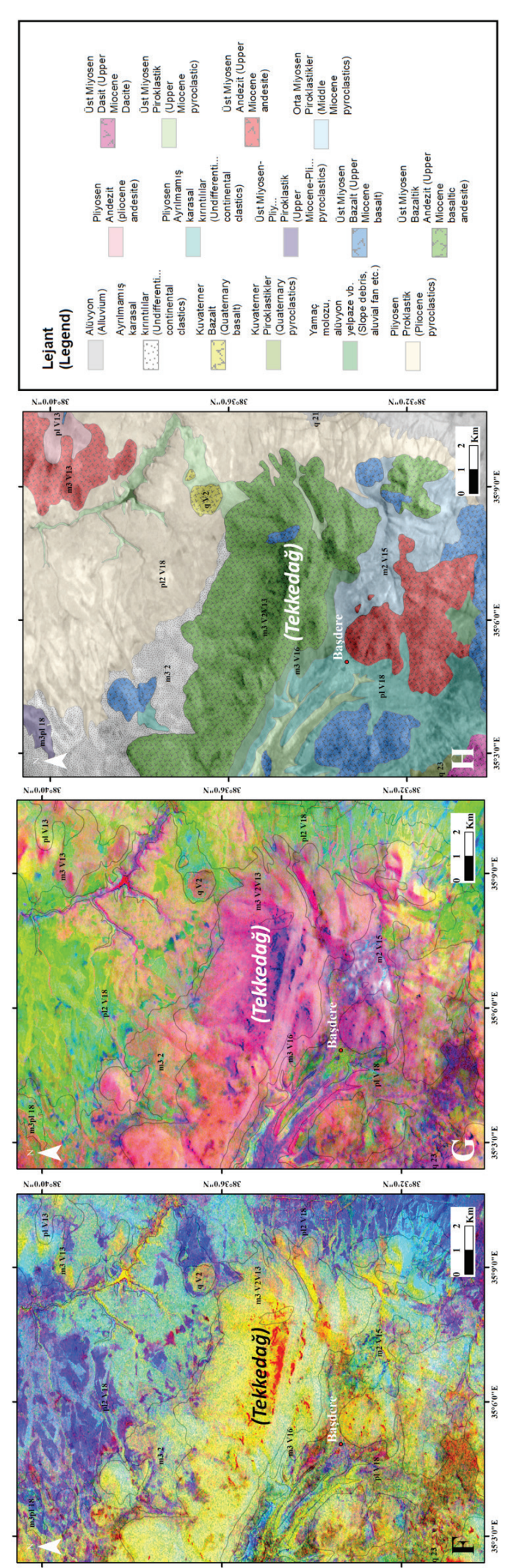

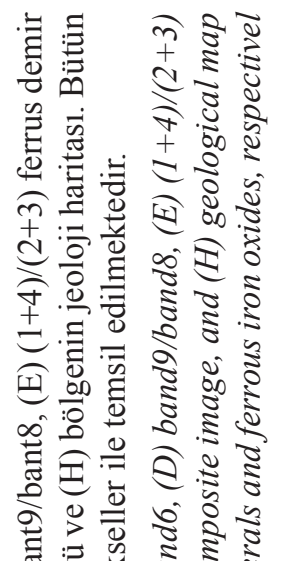

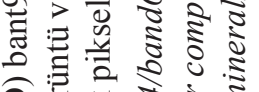

อิ:00

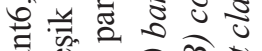

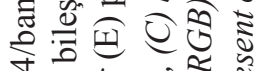

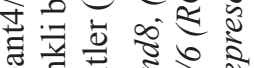

0 ए

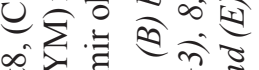

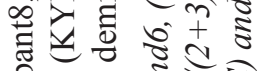

ชิ

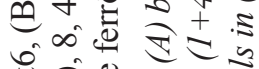

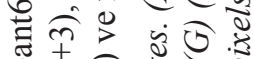

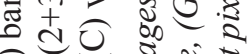

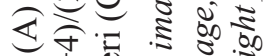

म

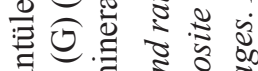

: : :

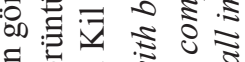

武: :

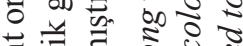

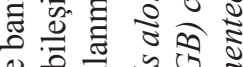

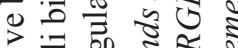

สే

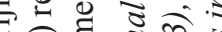

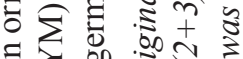

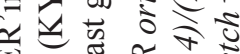

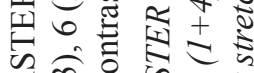

ये

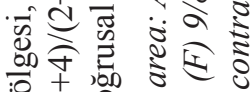

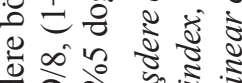

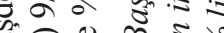

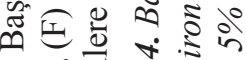

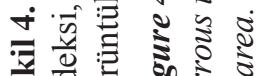

告告: 
(zayıf $\mathrm{Al}-\mathrm{OH}$ ve $\mathrm{Mg}-\mathrm{OH}$ soğurma bantları) ve bant4'e yakın yansıma oranı nedeniyle parlak pikseller ile temsil edilmiştir (Şekil 1B). Hamurcu ve Başdere beldelerinin yakın çevresinde görülen kırmızı alanlar alterasyonları işaret etmektedir (Şekil 1B).

\section{Bant Oran Görüntü Analizi}

Volkanik kayaçların sahip olduğu soğurma bantlarına odaklanarak oluşturulan gri ölçekli ve renkli bileşik bant oranlama görüntüleri oluşturulmuştur (Şekil 3 ve 4). Bununla birlikte, bant oran görüntülerinin parlaklık yoğunluğu açısından kör olduğu dikkate alınmalıdır (farklı cisimler benzer parlaklığa sahip olabilirler). $\mathrm{Bu}$ durumun üstesinden gelebilmek için bant oran görüntülerinde verinin orijinal bantlarından birinin anarenklerden birine tahsis edilmesiönerilmektedir (Lillesand vd., 2004). Bu doğrultuda, oluşturulan her iki bant oran görüntüsünde ASTER verisinin orijinal bantlarından bant6 ve bant8 (sirasiyla kayaçların $\mathrm{Al}-\mathrm{OH}$ ve $\mathrm{Fe} / \mathrm{Mg}-\mathrm{OH}$ soğurma bantlarına karşılık gelmektedir) kullanılmıştır (Şekil 2). Hamurcu (Susuzdağ, Kayseri) ve Başdere (Tekkedağ, Nevşehir) beldelerini içine alan bölgedeki bazalt, bazaltik andezit, andezit, dasit ve piroklastik kayaçların haritalanması amaciyla ASTER 9/8, $(1+4) /(2+3), 6$ ve $(1+4) /$ (2+3), 8, 4/6 (KYM) bant oranlarının renkli bileşik görüntüleri oluşturulmuştur (Şekil 3F,G ve Şekil 4F, G). ASTER' dan türetilen litoloji haritalarında jeoloji haritasına kıyasla bazı kayaçların sınırları daha iyi belirlenmiştir. Bant oran görüntülerinin her ikisinde de Fe kristal alan etkisi sonucu oluşan soğurma bantının belirlenmesi için Rockwell (2012)'in önerdiği $(1+4) /(2+3)$ ferrus demir indeksi kullanılmıştır. Gerek yanlış renk bileşik görüntüsünde gerekse bant oran görüntülerinde, Hamurcu ve Başdere beldeleri çevresinde görülen alterasyon sonucu oluşmuş mineraller (Şekil 3C, G ve Şekil 4C, G) arazi çalışmasında da gözlemlenmiştir (Şekil 5). Bölgedeki dasit ve
İncesu ignimbriti gibi volkanik kayaçlar, bazalt ve andezite göre daha yüksek miktarda felsik mineraller içerdiğinden dolayı, VNIR ve SWIR spektrum boyunca genel olarak yüksek yansıma oranı göstermektedir (Şekil 2, Şekil 3A, B ve Şekil 4A, B). Ayrıca, bölgedeki bazalt, bazaltik andezit ve andezitleri ASTER'in VNIR ve SWIR bantlarını kullanarak birbirinden ayırmak oldukça güçtür.

ASTER 9/8, (1+4)/(2+3), 6 (KYM) renkli bileşik görüntüde, $9 / 8$ bant oran görüntüsü bölgedeki volkanik kayaçlarda farklı oranlarda bulunan amfibol, piroksen, biyotit, epidot ve klorit ile ilişkilendirilen $\mathrm{Fe} / \mathrm{Mg}-\mathrm{OH}$ soğurma bantını vurgulamak için seçilmiştir (ASTER bant8'e karş1l1k gelen ferromagnezyen mineralleri derin $\mathrm{Fe} / \mathrm{Mg}-\mathrm{OH}$ soğurma bantı oluşturur) (Şekil 2). Bunun sonucu olarak, 9/8 bant oran görüntüsünde bazalt, bazaltik andezit ve andezitin çevresindeki felsik volkanik kayaçlara (dasit ve piroklastik) göre daha parlak pikseller olarak görülmesine neden olmuştur (Şekil 3D ve Şekil 4D). Örneğin, Hamurcu bölgesindeki kaldera da çevresindeki kayaçlardan daha açık tonlarda görülmektedir (Şekil 3D). Bununla birlikte, 9/8 bant oran görüntüsünde parlak piksellerin karbonatlı kayaçları da temsil edebilecek olsa da haritalanan bölgede karbonatlı kayaç bulunmadığını not etmek önemlidir. Dasit domlar1 $(1+4) /(2+3)$ bant oran görüntüsünde çevresindeki bazalt, bazaltik andezit, andezit ve piroklastik kayaçlara göre daha parlak piksellerle temsil edilmektedir (Şekil 3E). Bu durum dasit domlarının bazalt ve andezitlere k1yasla daha az altere olduğunun bir göstergesi olabilir. Özellikle Hamurcu kasabasının $\mathrm{KB}$ ve GB'sındaki dasit domları ile birlikte geniş bir alanda yayılmış olan İncesu ignimbriti (AlOH ile ilişkili) ASTER bant6'ya karşıllk gelen radyasyonu daha yüksek oranda yansıttığ 1 için bazaltik ve andezitik kayaçlara göre daha açık tonlarda görünmektedir (Şekil 3A ve Şekil 4A). Buna ilave olarak, 4/6 bant oranında İncesu 

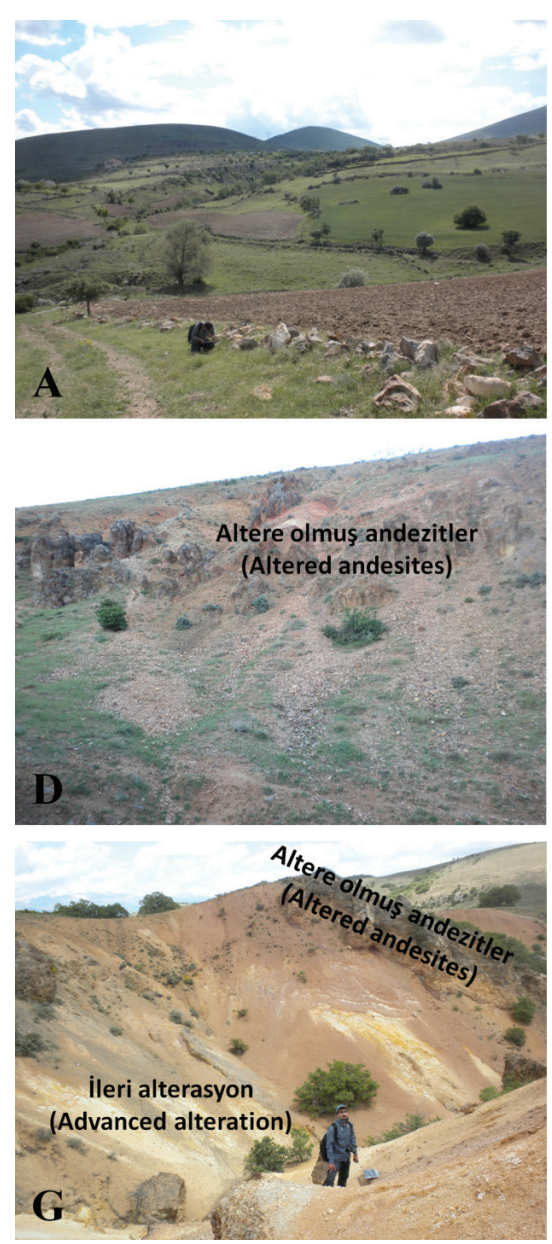
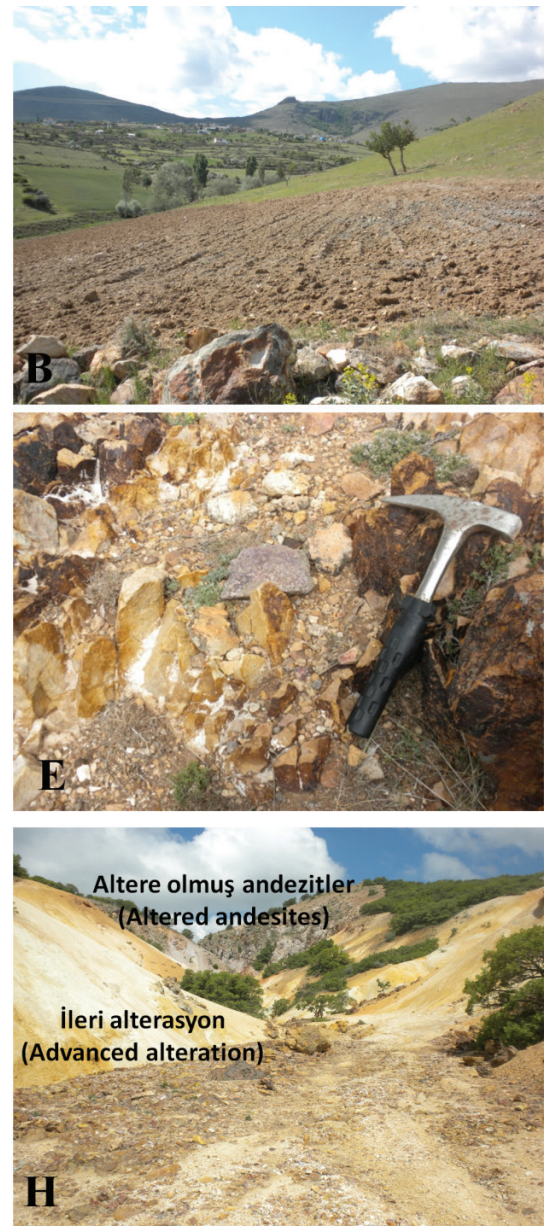
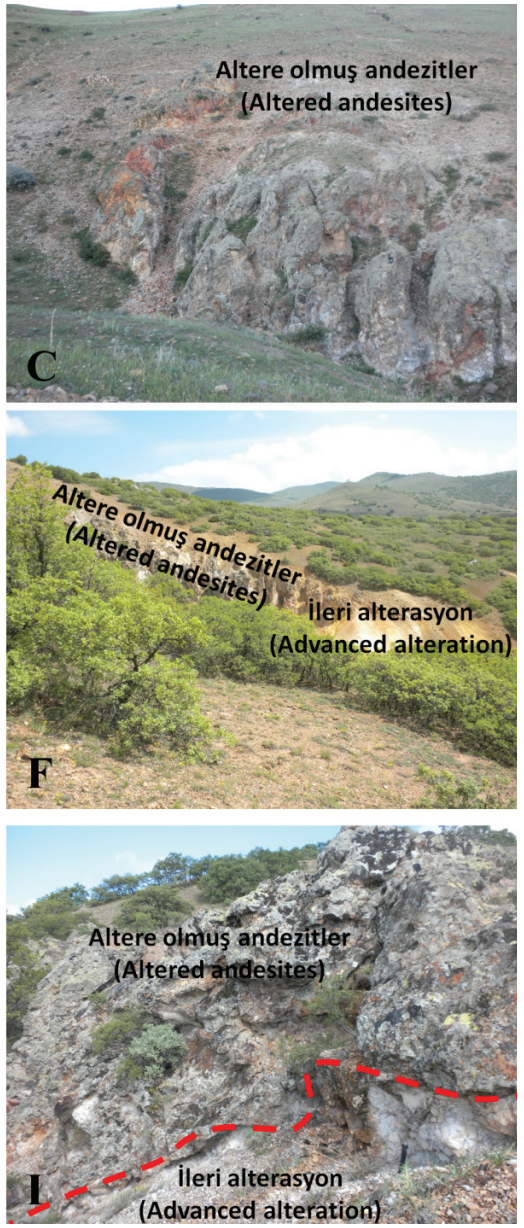

Şekil 5. (A, B) Hamurcu beldesi çevresindeki kalderanın doğudan batıya panoramik görünümü. (C, D) Hamurcu'nun doğusundaki vadi boyunca uzanan altere olmuş andezitler. (E) Hamucu çevresinde hemen hemen tamamen alunitleşmiş andezitler. (F, G, H) Başdere beldesinin güney doğusunda vadi boyunca uzanan altere olmuş andezitler ve vadi tabanındaki ileri alterasyon. (I) Başdere bölgesinde altere olmuş andezitin yakın görünümü ve tabanındaki ileri alterasyon arasındaki keskin alterasyon dokanağı.

Figure 5. (A, B) Panoramic view of the caldera from east to west around Hamurcu town. (C, D) Altered andesite along valley east of Hamurcu. (E) Andesite almost altered to alunite in vicinity of Hamurcu. $(F, G, H)$ Altered andesite along valley together with advanced alteration at base of valley southeast of Bassdere town. (I) Close view of altered andesite having sharp alteration line with advanced alteration at its base in Başdere area.

tonlarında görünmektedir (yüksek $9 / 8$ bant oranı ve bant6 ile birlikte düşük ferröz demir indeks yansıtma oranı nedeniyle). Hamurcu çevresindeki dasit domları ise bant6 ve ferrus demir indeksinde parlak pikseller ile temsil edilmesine rağmen, bant 9/8 oranındaki düşük yansıtma oranı nedeniyle yeşilimsi mavi renk ile temsil edilmektedir (Şekil $3 \mathrm{~F}$ ve Şekil 4F). İncesu ignimbriti ise özellikle yeşil renge karş111k gelen ferrus demir indeksinde koyu pikseller ile temsil edildiğinden (bant6'da ve bant $9 / 8$ oran görüntüsünde açık gri ve parlak pikseller olarak temsil edilmektedir) eflatun/mor ve lacivert renkler olarak görünmektedir. Kırmızı pikseller ise sağlıklı bitki örtüsünü (ekili alanları) işaret etmektedir (Şekil 3F ve Şekil 4F). 
ignimbritinin daha koyu pikseller olarak görünmesi de (Şekil 3C ve Şekil 4C) Al-OH soğurma bantının rölatif olarak zayıf olduğunu ve ignimbritlerin ileri derecede alterasyona maruz kalmadığının bir belirtisi olabilir. Renkli bileşik görüntüde (Şekil 3F ve Şekil 4F) ise bazalt, bazaltik andezit ve andezit sarı ve turuncu ASTER $(1+4) /(2+3), 8,4 / 6$ (KYM) bant oran görüntüsünde ise Hamurcu beldesi çevresindeki dasit domları ve dasitik kayaçlar açık sarı renk ile temsil edilmektedir (Şekil 3G). Bunun nedeni, (1) $(1+4) /(2+3)$ bant oranında dasit domlarının yüksek yansıma oranına sahip olması (Şekil 3E) (başka bir ifadeyle bant3'teki düşük yansıma değeri), (2) bant8'de dasitin bir dereceye kadar yüksek yansıtma kabiliyeti (Şekil 3B) (dasitin $\mathrm{Fe} / \mathrm{Mg}-\mathrm{OH}$ ile ilişkili soğurma bantının oldukça zayıf olmasi) ve (3) dasitin 4/6 bant oranındaki düşük parlaklık değeridir (Şekil 3C) (bant6'da dasit diğer volkanik kayaçlara göre daha yüksek yansıtma oranına sahiptir (Şekil 3A)). Öte yandan, bölgede geniş alanlara yayılmış piroklastik kayaçlar (İncesu ignimbriti), bant8'e karşı1lık gelen radyasyonu bazalt ve andezitlere göre daha fazla yansıtıp (Şekil 3B ve Şekil 4B), bant3 ve bant6' da derin soğurma bantına sahip olmamasından dolayı $((1+4) /(2+3)$ ve $4 / 6$ bant oran görüntülerinde bölgedeki diğer volkanik kayaçlara göre daha koyu tonlardadır (sırasıyla, Şekil 3E, C ve Şekil 4E, C)). Piroklastik kayaçlar ASTER $(1+4) /(2+3)$, 8, 4/6 (KYM) bant oran görüntüsünde yeşilimsi sarı (ekili olmayan tarım alanları) ve yeşilin farklı tonlarında görünmektedir (Şekil $3 G$ ve Şekil 4G). Bölgedeki bazalt, bazaltik andezit ve andezit ise özellikle ASTER bant8'deki nispeten derin ve karakteristik $\mathrm{Fe} / \mathrm{Mg}-\mathrm{OH}$ soğurma bantı nedeniyle pembe ve mor renkler ile temsil edilmektedir (Şekil 3G ve Şekil 4G). Hamurcu çevresinde ve Başdere beldesinin GD'sunda görülen alterasyonlar beyazımsı açık mavi renkler olarak görülmektedir (Şekil $3 G$ ve Şekil 4G). Hamurcu ve Başdere beldeleri yakınında arazi çalışmasında da gözlemlenen alterasyonlar 4/6 bant oranında parlak pikseller olarak görünüp kil mineralleri ile ilişkilidir (Şekil 3C ve Şekil 4C). Renkli bileşik görüntüde mavi/lacivert renk sağlıklı bitki örtüsü (ekili alanlar) işaret etmektedir (Şekil 3G ve Şekil $4 G)$.

\section{EXTENDED SUMMARY}

The study area around the towns of Hamurcu and Basdere is located in the W-SW part of Kayseri province in central Anatolia (Turkey) (Figure 1). The Hamurcu and Başdere areas, which resemble calderas, lie within the $\mathrm{NE}-\mathrm{SW}$-trending Cappadocia Volcanic Terrain (CVT) in the northern part of the Kayseri pull-apart basin. (Ak et al., 2015). The ages of the andesitic volcanism in Tekkedăg (Başdere) and Hamurcu indicate the upper and middle-upper Miocene periods, respectively (Dönmez et al., 2003).

Satellite images provide a practical and costeffective way of delineating different kinds of rocks. The ASTER multispectral sensor measures reflected radiation in three VNIR bands, six SWIR bands, and five TIR bands with a spatial resolution of $15 \mathrm{~m}, 30 \mathrm{~m}$ and $90 \mathrm{~m}$, respectively (Fujisada, 1995). The study area is underlain by a crystalline massif known as the Central Anatolian Crystalline Complex (CACC) which is a part of the Anatolide platform (Delibaş and Genç, 2012). The CACC is composed of a metamorphic core cut by late Cretaceous granitoids of various origin during and subsequent to the closure of the Neotethyan oceanic plate (Delibaş and Genç, 2012). While a compressional tectonic regime led to crustal shortening and the emplacement of plutons until late Cretaceous (Genç and Yürür, 2010), the metamorphic basement of the CACC was uplifted due to stretching and thinning of the crust by an extensional tectonic regime following late Cretaceous (Seyitoğlu and Scott, 1996). The CVT is a back arc basin formed because of the collision of the Eurasian and Afro-Arabic plates in a broad region during the Middle-Late Miocene 
and Quaternary period (Innocenti et al., 1975; Rotstein and Kafka, 1982).

This study presents and describes two novel band ratio images $(9 / 8,(1+4) /(2+3), 6$ and $(1+4) /$ $(2+3), 8,4 / 6$ in $R G B)$ for the mapping of extrusive igneous rocks using ASTER VNIR and SWIR data around the Hamurcu (Susuzdăg, Kayseri) and Başdere (Tekkedăg, Nevşehir) areas in central Anatolia, Turkey. Diagnostic Fe, Al-OH and Fel $\mathrm{Mg}-\mathrm{OH}$ absorption features pertaining to the extrusive igneous rocks in the study area were the main focus in generating band ratio images. Band ratios of $(1+4) /(2+3), 4 / 6$ and $9 / 8$ delineate dacite domes, pyroclastic rocks and basalt/andesite, respectively. Basalt and andesite in comparison with the rest of the surrounding volcanic rocks appear as much brighter pixels in the 9/8 band ratio image (Figures $3 D$ and $4 D$ ). While the dacite domes having high reflectance around Hamurcu can be delineated by the ferrous iron index $(1+4) /$ (2+3) (Figure 3E), pyroclastic rocks, Incesu ignimbrite in particular, that extend in the large lowlands appear as darker tones (Figures 3C and $4 C)$.

Hamurcu and Başdere are ideal sites for remote sensing in mapping volcanic rocks because the study region has a semi-arid terrain with good bedrock exposure and scattered and sparse vegetation cover. Note also that, to my knowledge, the rocks in the study area have not previously been mapped with remotely sensed data. Moreover, field observations in conjunction with the geological map validate the ASTER-derived lithological maps. As a result, the developed band ratio images implemented to the ASTER data proved to be a powerful tool for generating preliminary, rapid, accurate and reliable lithological maps at low cost in similar terrain at different geographic locations.

\section{KATKI BELİRTME}

Özellikle Kocaeli Üniversitesi BAP birimine bu projeyi desteklediği için teşekkür ederim. Ayrıca, arazi çalışmasına katılan doktora öğrencim Jeoloji Yüksek Mühendisi Kemal Anıl Tözün'e ve ASTER görüntüsünü ücretsiz olarak sağladığı için USGS Earth Resources Observation and Science (EROS) merkezine teşekkürü bir borç bilirim.

\section{ORCID}

Aziz Özyavas (D https://orcid.org/0000-0003-4178-2750

\section{DEĞİNILEN BELGELER / REFERENCES}

Ak, S., Yumuk, O., Yıldız, H., Mengeloğlu, M., 2015. Hamurcu-(İncesu-Kayseri ve Başdere (Yeşilhisar-Kayseri) Au-Ag-Cu-Mo-Pb-ZnAs Cevherleşmesi. MTA Doğal Kaynaklar ve Ekonomi Bülteni, 20, 85-95.

Akçay, A.E., Dönmez, M., Türkecan, A., 2017. Sultan sazlığı havzasının (Kayseri) açılım yaşına ilişkin jeolojik veriler. MTA Doğal Kaynaklar ve Ekonomi Bülteni, 22, 57-62.

Amer, R., Kusky, T., Ghulam, A., 2010. Lithological mapping in the central eastern desert of Egypt using ASTER data. Journal of African Earth Sciences, 56 (2), 75-82.

Batum, I., 1978. Nevşehir güneybatısındaki Göllüdağ ve Acıgöl yöresi volkanitlerinin jeoloji ve petrografisi. Hacettepe Universitesi YerbilimleriBulletin for Earth Sciences, (3) 50-69.

Chabrillat, S., Goetz, A.F.H., Krosley, L., Olsen, H.W., 2002. Use of hyperspectral images in the identification and mapping of expansive clay soils and the role of spatial resolution. Remote Sensing of Environment, 82, 431-445.

Clark, R.N., 1999. Spectroscopy of rocks and minerals and principles of spectroscopy (Remote sensing for the earth sciences, manual of remote sensing, Ed.: Rencz, A.N.). John Wiley and Sons, New York, 3-58. 
Delibaş, O., Genç, Y., 2012. Late Cretaceous coeval acidic and basic magmatism, Karacaali magmatic complex, central Anatolia, Turkey. International Geology Review, 54 (14), 1697-1720.

Dhont, D., Chorowicz J., Yürür T., Froger J.-L., Köse O., Gündoğdu N., 1998. Emplacement of volcanic vents and geodynamics of Central Anatolia, Turkey. Journal of Volcanology and Geothermal Research, 85, 33-54.

Dönmez, M., Türkecan, A., Akçay, A.E., 2003. Kayseri - Niğde - Nevşehir yöresi Tersiyer volkanitleri. Maden Tetkik ve Arama Genel Müdürlüğü, Rapor No:10575 Ankara, (yayımlanmamış).

Dönmez, M., Akçay, A.E., Türkecan, A., 2005. 1/100.000 ölçekli Türkiye Jeoloji Haritaları serisi. Kayseri - K34 paftasi: No: 49, Maden Tetkik ve Arama Genel Müdürlüğü Yayını.

Drury, S., 2001. Image interpretation in geology. Blackwell Science, Malden, MA, 304 s.

Ercan, T., 1986. Orta, Anadolu'daki Senozoyik volkanizmasi. Bulletin of the Mineral Research and Exploration, 107, 119-140.

Fujisada, H., 1995. Design and performance of ASTER instrument. Proceedings of SPIE, the International Society for Optical Engineering, 2583, 16-25.

Genç, Y., Yürür, T., 2010. Coeval extension and compression in Late Mesozoic-Recent thinskinned extensional tectonics in central Anatolia, Turkey. Journal of Structural Geology, 32, 623-640.

Göncüoğlu, M., 2010. Türkiye Jeolojisine Giriş: Alpin ve Alpin Öncesi Tektonik Birliklerin Jeodinamik Evrimi. Maden Tetkik ve Arama Genel Müdürlüğü Yayınları, Monografi Serisi: 5, Ankara, 69 s.

Haselwimmer, C.E., Riley, T.R., Liu, J.G., 2010. Assessing the potential of multispectral remote sensing forlithological mapping on the Antarctic Peninsula: case study from eastern Adelaide Island, Graham Land, Antarctic Science, 22, (3), 299-318.
Hunt, G.R., Salisbury, J.W., Lenhoff, C.J., 1974. Visible and near infrared spectra of minerals and rocks: IX. Basic and ultrabasic igneous rocks. Modern Geology, 5, 15-22.

Idleman, L., Cosca, M.A., Heizler, M.T., Thomson, S.N., Teyssier, C., Whitney, D.L., 2014. Tectonic burial and exhumation cycles tracked by muscovite and $\mathrm{K}$-feldspar ${ }^{40} \mathrm{Ar} /{ }^{39} \mathrm{Ar}$ thermochronology in a strike-slip fault zone. Tectonophysics, 612-613, 134-146.

Innocenti, F., Mazzudi, R., Pasquare, G., Radicati, Brozolo F., Villari, L., 1975. The Neogene calc-alkaline volcanism of Central Anatolia: Geochronological data on Kayseri-Niğde area: Geological Magazine, 112, 349-360.

Keskin, H., Dönmez, M., Akçay, A.E., 2010. 1/100.000 ölçekli Türkiye Jeoloji haritaları, Kayseri L34 paftas1, No: 141 Maden Tetkik ve Arama Genel Müdürlüğü Yayını, Ankara.

Koçyiğit, A., Erol, O., 2001. A tectonic escape structure: Erciyes pull-apart basin, Kayseri, central Anatolia, Turkey. Geodinamica Acta, 14, 133-145.

Koralay, T., Kadığlu, Y.K., 2003. İgnimbiritlerin tavan ve taban ilişkilerini belirleyen petrografik veriler: İncesu (Kayseri) ignimbiriti. Selçuk Üniversitesi Mühendislik-Mimarlık Fakültesi Dergisi 18 (1), 43-54.

Koralay, T., 2006. İncesu ignimbiritinin (Kayseri) Jeolojisi, Petrolojisi ve Ayırtman Özellikleri. Ankara Üniversitesi, Doktora Tezi., 302 s., (yayımlanmamış).

Le Pennec, J.L., Bourdier, J.L., Froger, J.L., Temel, A., Camus, G., Gourgaud, A., 1994. Neogene Ignimbrites of the Nevsehir plateau (Central Turkey): stratigraphy, distribution and source constraints. Journal of Volcanology and Geothermal Research, 63 (1-2), 59-87.

Le Pennec, J.L., Temel, A., Froger, J.L., Şen, Ş., Gourgaud, A., Bourdier, J.L., 2005. Stratigraphy 
and age of the Cappadocia ignimbrites, Turkey reconciling field constraints with paleontologic, radiochronologic, geochemical and paleomagnetic data. Journal of Volcanology and Geothermal Research, 141, 45-64.

Lillesand, T., Kiefer, R.W., Chipman, J., 2004. Remote Sensing and Image Interpretation, 5. ed. Wiley India Pvt. Limited, $763 \mathrm{~s}$.

Mars, J.C., 2010. VINR-SWIR and TIR remote sensing of porphyry copper deposits, (Porphyry Copper Deposit Model, Ed.: John, D.A.). Scientific Investigations Report, 5070-B, 38-50.

Mars, J.C., Rowan, L.C., 2010. Spectral Assessment of New ASTER SWIR Surface Reflectance Data Products for Spectroscopic Mapping of Rocks and Minerals. Remote Sensing of Environment, 114, 2011-2025.

Pasquare, G., 1968. Geology of the Cenozoic volcanic area of Central Anatolia. Accademia nazionale dei Lincei, 8 (9), 53-204.

Pasquare, G., Poli, S., Vezzoli, L., Zanchi, A., 1988. Continental arc volcanism and tectonic setting in Central Anatolia, Turkey. Tectonophysics, 146, 217-230.

Pour A.M., Hashim M., 2012. The application of ASTER remote sensing data to porphyry copper and epithermal gold deposit. Ore Geology Reviews, 44, 1-9.

Rajendran, S., Nasir, S., 2017. Characterization of ASTER spectral bands for mapping of alteration zones of volcanogenic massive sulphide deposits. Ore Geology Reviews, 88, 317-335.

Rockwell, B.W., 2012. Description and Validation of an Automated Methodology for Mapping Mineralogy, Vegetation, and Hydrothermal Alteration Type from ASTER Satellite Imagery with Examples from the San Juan Mountains, Colorado: Scientific Investigations Map 3190.
Rotstein Y., Kafka A.L., 1982. Seismotectonics of the southern boundary of Anatolia, Eastern Mediterranean region: subduction, collision and arc jumping Journal of Geophysical Research: Solid Earth, 87 (B9), 7694-7706.

Rowan, L.C., Mars, J.C., 2003. Lithologic Mapping in the Mountain Pass, California Area Using Advanced Spaceborne Thermal Emission and Reflection Radiometer (ASTER) Data. Remote Sensing of Environment, 84, 350-366.

Schumacher, R., Keller, J., Bayhan, H., 1990. Depositional characteristics of ignimbrites in Cappadocia, Central Anatolia, Turkey. Proceedings of IESCA Congress. (Ed. Savaşcın, Y., Eronat, H.A.,), 2, 435-449.

Schumacher, U.M., Schumacher, R., Götte-Viereck, G.L., Lepetit, P., 2004. Areal Distribution and Bulk Rock Density Variations of the Welded İncesu Ignimbrite, Central Anatolia, Turkey. Turkish Journal of Earth Sciences, 13 (3), 249-267.

Seyitoğlu, G., Scott, B.C., 1996. The cause of N-S extensional tectonics in western Turkey: tectonic escape vs back-arc spreading vs orogenic collapse. Journal of Geodynamics, 22, 145-153.

Tommaso, I.M., Rubinstein, N., 2007. Hydrothermal alteration mapping using ASTER data in the Infiernillo porphyry deposit, Argentina. Ore Geology Reviews, 32, 275-290.

Toprak, V., 1998. Vent distribution and its relation to regional tectonics, Cappadocia Volcanics, Turkey. Journal of Volcanology and Geothermal Research, 85 (1-4), 55-67.

Toprak, V., Keller, J., Schumacher, R., 1994. Volcano tectonic features of the Cappadocian volcanic province. International Volcanological Congress, IAVCEI'94, Excursion Guide. Ankara.

Türkecan, A., Dönmez, M., Akçay, A., 2003. KayseriNiğde-Nevşehir Yöresi Tersiyer Volkanitleri. Maden Tetkik ve Arama Genel Müdürlüğü, Rapor no: 10575. (yayımlanmamış). 
Yamaguchi, Y., Naito, C., 2003. Spectral Indices for Lithologic Discrimination and Mapping by Using the ASTER SWIR Bands. International Journal of Remote Sensing, 24, 4311-4323.
Zhou, K., Wang, S., 2017. Spectral properties of weathered and fresh rock surfaces in the Xiemisitai metallogenic belt, NW Xinjiang, China. Open Geosciences, 9, 322-339. 